\title{
Züchterische Aspekte der einheimischen Eiweissversorgung im Norden
}

\author{
ERKKI KIVI \\ Hankkija Pflanzenzüchtungsinstitut, SF-04300 Hyrylä, Finnland
}

\section{A plant breeder's viewpoints on domestic protein production at northern latitudes}

\author{
E. I. KIVI \\ Hankkija Plant Breeding Institute, SF-04300 Hyrylä, Finland
}

\begin{abstract}
This paper is based on a lecture given in June, 1978 at the Central Institute Colloqium of the Academy of Science of the German Democratic Republic at Gatersleben. It deals with problems of breeding for improved domestic feed protein production in Finland.

In recent years, there has been a reappraisal of the value of red clover, both as a protein source in ley husbandry and as a natural nitrogen producer in crop rotations. Further breeding efforts are needed towards disease resistance and persistence in red clover.

In the North, the most reliable species for seed protein production are the pea, faba bean, and the annual forms of rape and turnip rape.

To improve the reliability of peas, material from the VIR genebank, Leningrad, USSR, has been used in crosses. Both semileafless and small-seeded lines have been selected and these lines are already in official performance trials.

In faba bean, very early ripening and small-seeded material was collected in 1969 from Carelian local bean populations in southeast Finland.

Both in rape and turnip-rape mutation breeding has been used to produce types reliable under northern conditions.
\end{abstract}

\section{Einleitung}

Ein Pflanzenzüchter, der zum praktischen Ziele strebt, soll nicht nur die Quantität und die Qualitätscharakteristika der Ernte sondern auch die Umgebung, wo der Anbau seiner Sorten zur Ausführung gebracht wird, berücksichtigen. Die Veränderung in einer Eigenschaft hat immer Einflüsse auf viele andere Anbaucharakteristika und dafür wird es für einen Pflanzenzüchter oft schwieriger sein, z.B. nach den neuen Forderungen der Qualitätseigenschaften, das schon errungen ökonomische Niveau der Produktion oder 
die Sicherheit des Anbaus beizubehalten, als die auf neue Qualität positiv einwirkenden Erbfaktoren durch Kreuzungen ins Zuchtmaterial zu übertragen. Mit dieser Problematik kollidieren wir nicht gar selten in der heutigen Züchtungsarbeit.

In vielen europäischen Ländern ist man in den letzten Jahren bemüht gewesen, die einheimische Futtereiweissproduktion zu vermehren, wegen der intensivierten Tierwirtschaft und, vor allem, wegen der Begrenzungen der Weltmarkt der bisherigen Eiweissquellen, wie Sojabohne oder Fischmehl. Finnland ist eines von den Ländern, wo der Import der Eiweissfuttermittel streng reguliert worden ist. Dies hat zur Folge gehabt, dass die Verbesserung der Eiweisseigensschaften der einheimischen Kulturen sowohl in der Praxis als auch in der Forschung der Mittelpunkt der Anstrengungen geworden ist.

Alle Bestrebungen, um die Eiweissproduktion auszubauen, bedeuten also, ausser dem Steigen der Erträge und dem Heben des Qualitätsniveaus des pflanzlichen Eiweisses, auch die Erhaltung der heutigen Anbausincherheit, in vielen Fällen sogar die Verbesserung derselben. Auf unseren Breitengraden sind die Aspekte der Züchtung für bessere Eiweisseigenschaften eher Züchtung auf bessere Umweltadaptation bei den Arten, die gute Eiweisscharakteristika haben, als die genetische Manipulation der Eiweissfaktoren selbst.

\section{Die Hauptlinien des Ackerbaus in Finnland}

Finnland ist der Welt nördlichstes Land, das die vollkommene Selbstversorgung an ackerbaulichen Pflanzenprodukten erreicht. Schon im Vergleich mit den nächsten skandinavischen Nachbarn liegt Finnland landwirtschaftlich sehr hoch im Norden (Abb. 1). Das ganze Land liegt nördlich vom 60. Breitengrad. Schweden ist so viel südlicher als Finnland, dass 92 Prozent der Getreideproduktion südlich von der Südküste Finnlands erfolgt.

Der Schwerpunkt des finnischen Ackerbaus liegt in den südlichen Teilen des Landes. Die Karte (Abb. 2) zeigt die 90-Prozent-Grenzen der sogenannten grossen Ackerbaugruppen, des Brot- und Futtergetreides und Grasbaus. Die Grenzen bedeuten also, dass 10 Prozent des Anbaus noch nordöstlich von denen stattfindet. Wir sehen z. B., dass ein bedeutender Anteil des Futtergetreides, also der Sommergerste und des Hafers, nördlich von dem 62. Breitengrad angebaut wird. Diese Breite wird in der skandinavischen Landwirtschaft als Südgrenze des sogenannten Nordkalottgebietes betrachtet (KIVI 1965). Die Konzentrierung der Tierwirtschaft in den inneren und nördlichen Teilen des Landes ist auf der fernliegenden Nordgrenze des Grasbaus deutlich zu sehen. Die Ackerpflanzen, die dort oben angebaut werden, müssen ihre Ernte nach den Einwirkungen des sehr langen und strengen Winters und unter den extremsten photoperiodischen Verhältnissen des Sommers produzieren. Spezialcharakteristika der nördlichen Lage sind u. a., dass etwa 80 Prozent der Gerste frühreifende mehrzeilige Sorten sind, oder, dass beim Weizen die Sommersorten

grössere Bedeutung als Winterweizen haben, denn, wegen der begrenzten Überwinterungsfähigkeit sogar der einheimischen Sorten, können wir Winterweizen nur im Südwesten anbauen. 


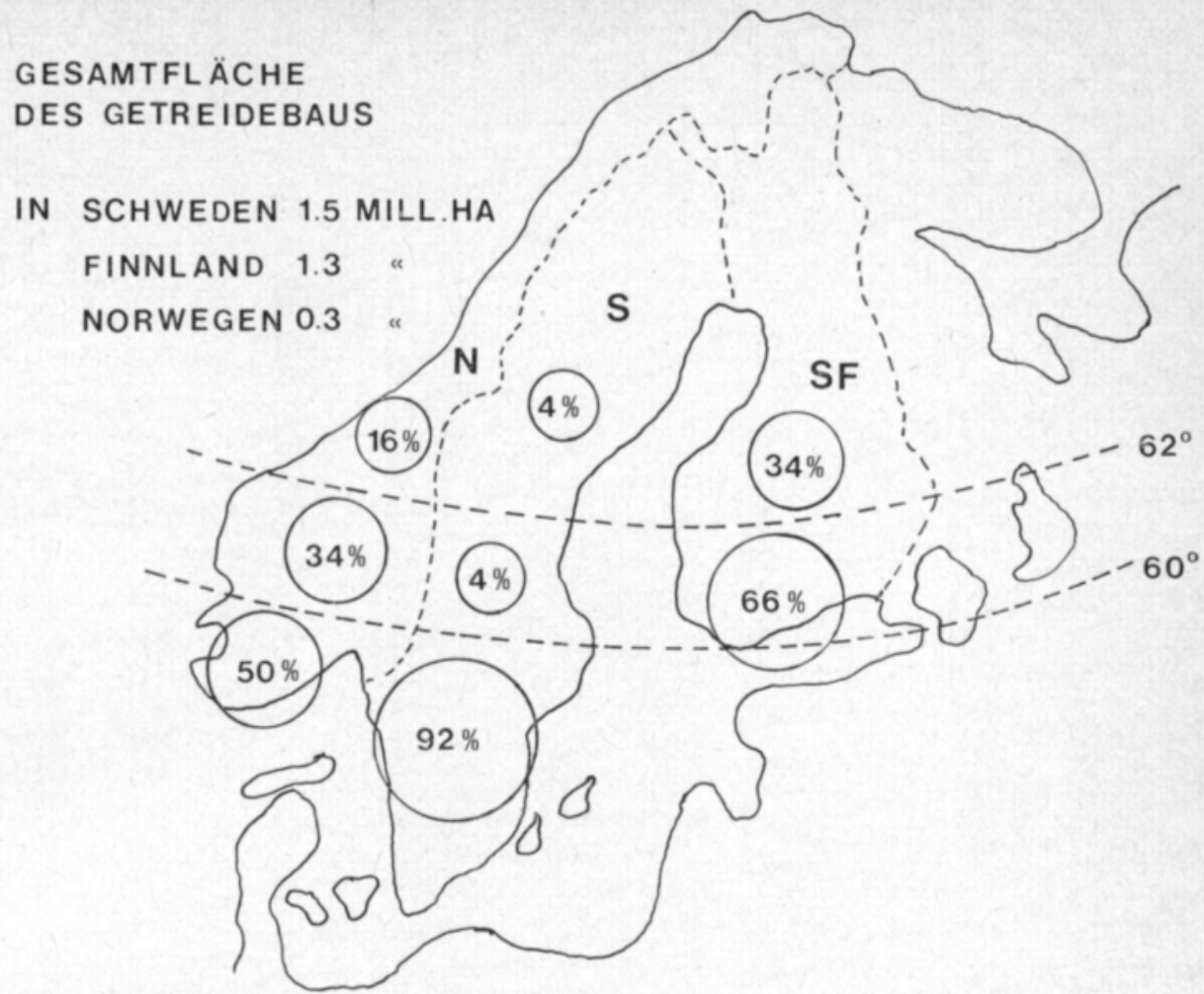

Abb. 1. Die Verteilung der Getreideflächen der nördlichen Länder auf gewisse Breitengrade (nach den offiziellen Statistiken $1974-75$ der gebührenden Länder).

\section{Wachstumsfaktoren im Norden}

Die nördliche Lage Finnlands führt zu vielen klimatischen Charakteristika. In der Abbildung 3 sind zwei von denen auf Grund der Resultate der europäischen Braugerstenversuche, EBC-Versuche, schematisiert (LANG 1966, KIvI 1967). Im Vergleich mit Dänemark und den Niederlanden ist die Wachstumsperiode in Finnland kurz. Der Sommer bei uns ist eigentlich nicht mehr als ein Sprung in den Sommer; im Juli, wenn sich die Temperatur den Wärmeverhältnissen der südlicheren Länder nähert.

Im Schema (Abb. 3 a) sind auch drei Phasen des Wachstums der Gerste - als Mittelwerte der drei zweizeiligen Braugersten -, nähmlich Aussaat, Ährenschieben und Reifen enthalten. Wir sehen, dass wenn man in SüdFinnland im Mai säet, das Wetter schon wärmer ist als in Dänemark oder in den Niederlanden während und nach der Aussaat. Die Temperatur steigt rasch bis zum Ährenschieben, und darum ist die vegetative Phase der Entwicklung der Gerste bei uns viel schneller als im Süden. Das Wachstum der zweizeiligen Gerste dauert in Finnland nur 97 Tage, 122 Tage in Dänemark und ganz und gar 135 Tage unter dem maritimen Klima der Niederlande. Wenn der Entwicklungsrhytmus der Gerste so langsam in Finnland wie in Dänemark wäre, könnten wir eigentlich kein Getreide, gar keine reife Samen erzeugende Pflanzen anbauen! 


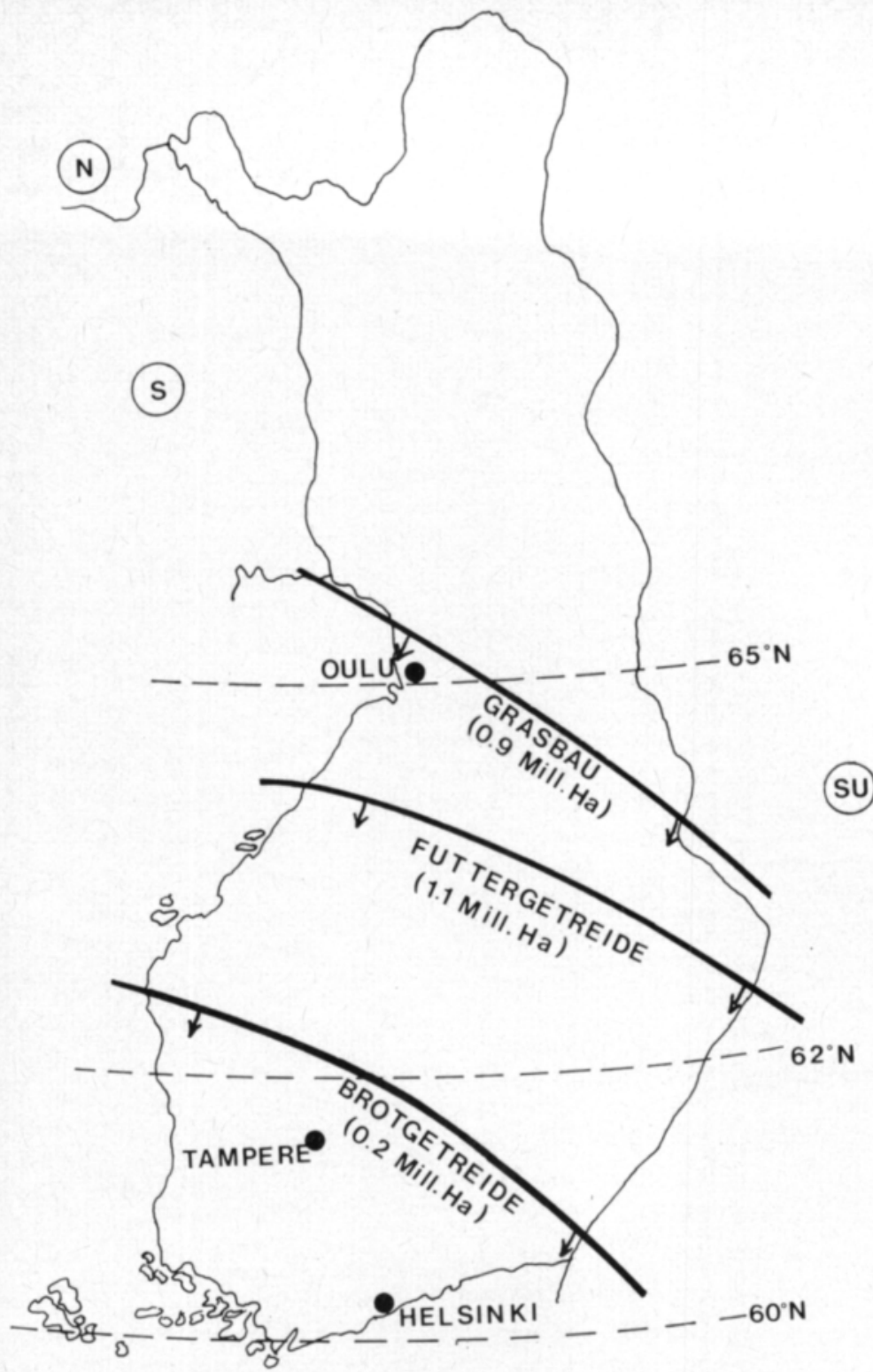

Abb. 2. Die 90-Prozent-Grenzen des Anbaus des Brot- und Futtergetreides und Grases in Finnland. 90 Prozent von der Produktion der jeden Pflanzengruppe findet südwestlich von der Grenzlinie statt (nach den Ziffern der offiziellen Statistik Finnlands 1977 schematisiert).

Ein anderer Faktor ist die Lichtmenge, Tageslänge, die ebenfalls am Anfang der Wachstumsperiode, nach der Aussaat, im Maximum ist. In der Abb. 3 b werden die Unterschiede zwischen den drei Ländern auf Grund der Menge der Sonnenscheinstunden pro Monat geschildert. Während der Aussaat und unmittelbar danach haben wir also wenigstens doppelt so viel Sonnenschein, Licht im allgemeinen, als in den Niederlanden in den ersten Wochen des 

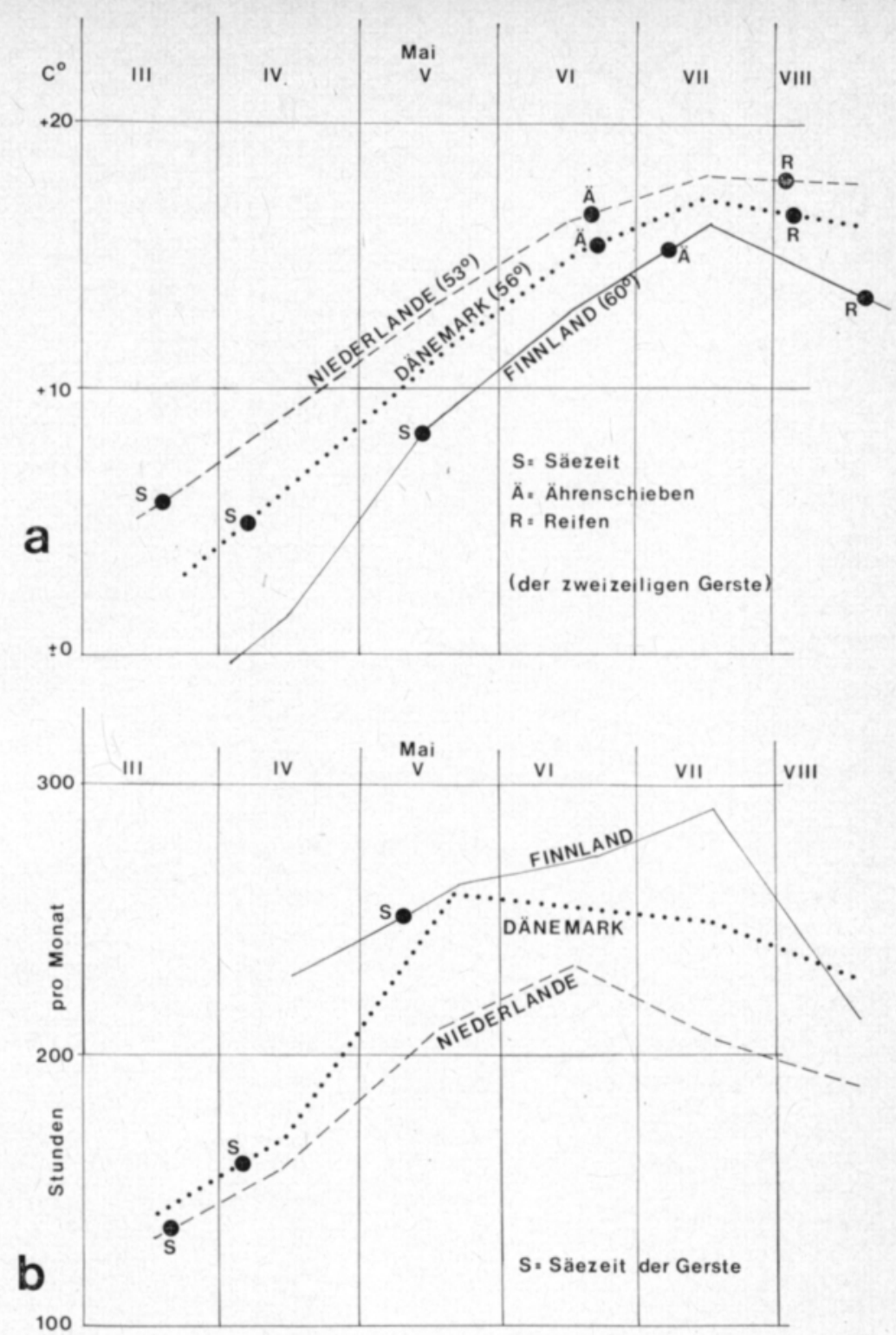

Abb. 3. Die Temperatur- (a) und Sonnenscheinverhältnisse (b) der Wachstumsperiode in drei europäischen Ländern (näher im Text).

Wachstums. Bei Zunahme des Regens im Spätsommer fällt die Sonnenscheinkurve schon im August stark ab.

Die Wärme ist ohne weiteres der wichtigste Minimumfaktor unseres Pflanzenbaus und der Wärmebedarf der Arten und Sorten reguliert ihre Anbausicherheit.

Die Wärme eines Sommers wird oft mit der Wärmesumme oder mit sogenannter "Summe der effektiven Temperaturgrade" gemessen. Dieser Begriff ist ursprünglich von den Forstbiologen dargestellt worden (SARVAS 1965), und sie ist die Summe der täglichen. Mitteltemperaturen, doch auf solche 


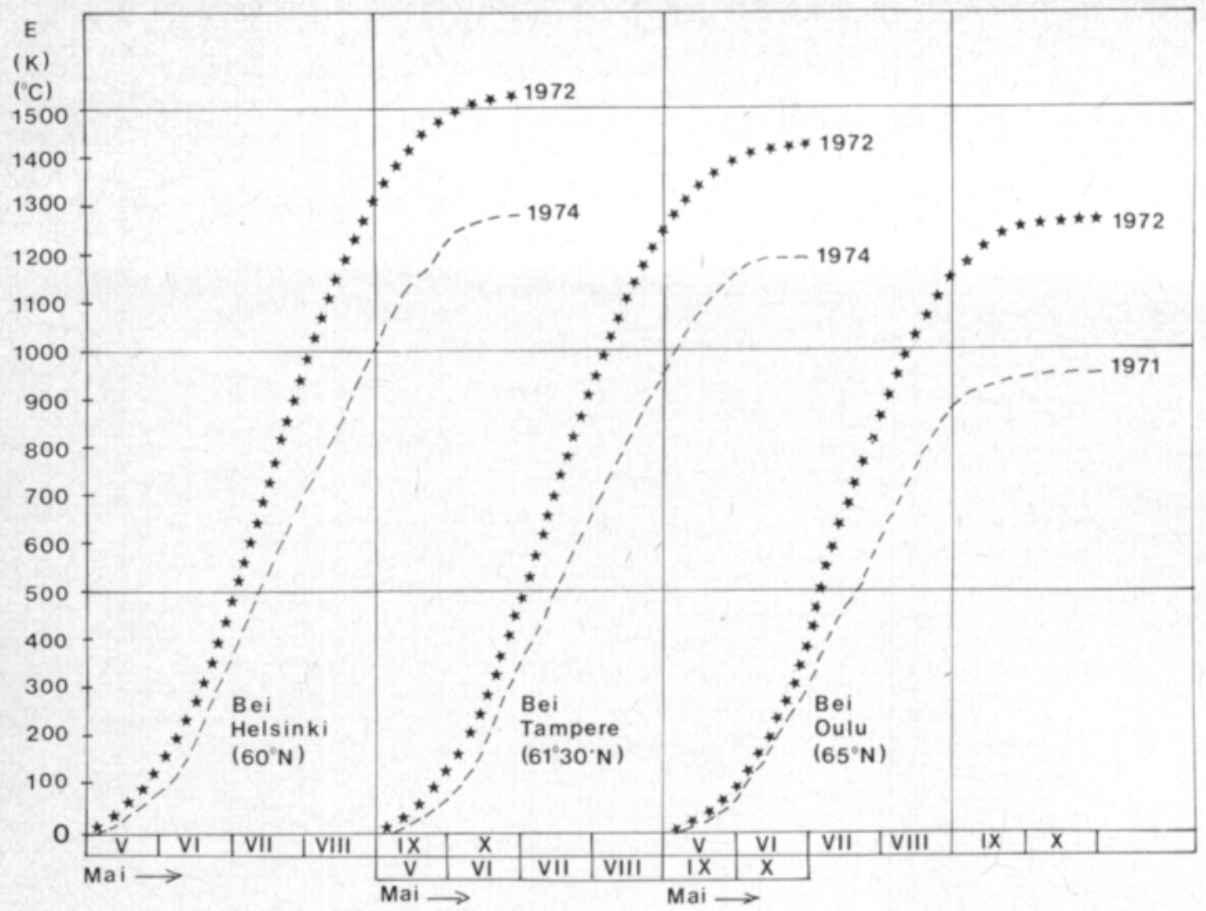

Abb. 4. Die Entwicklung der effektiven Wärmesumme in einem kalten und warmen Sommer der 70er Jahre bei drei Orten in Finnland (nach REKUNEN 1975).

Weise gerechnet, dass nur die Anteile der täglichen Mittelwerte, die $+5^{\circ} \mathrm{C}$ übersteigen, zusammengerechnet werden. Diese Grenze ist deshalb als Grundwert genommen, weil die höheren Pflanzen im allgemeinen nicht unter $+5^{\circ} \mathrm{C}$ wachsen.

Die effektive Temperaturkurve beginnt normalerweise Anfang Mai zusteigen, und ihr Steigen erreicht das Maximum natürlich im Juli. Oft sind die täglichen Tagestemperaturen schon im September so niedrig, dass die Steigerung der Kurve sogar in Süd-Finnland ein Ende macht. Im Laufe der Wachstumsperiode steigt die effektive Temperaturkurve bis zu 900-1400 Grad, abhängig von der geographischen Breite.

Jährliche Variabilität der Temperatursumme ist gross. In der Abbildung 4 gibt es Kurven für einen warmen und für einen kühlen Sommer der 70er Jahre. Der Sommer 1972 war sehr warm im ganzen Land, 1974 war kalt im Süden, 1971 im Norden. Wir sehen auch, dass die wärmste Periode in NordFinnland, in 1972, war ungefähr ebenso kalt wie der kalte Sommer 1974 in Süd-Finnland. Der Übergang nach Norden stellt also immer grössere Forderungen an die Milieuresistenz der Pflanzen.

Eine Sorte braucht fürs Reifen eine umso höhere Temperatursumme je länger ihre Wachstumszeit ist. Um anbausicher genug zu sein, muss die Sorte so früh reifen, dass sie auch in solchen Sommern, wo die Wärme unter dem normalen liegt, das Erntestadium erreicht bevor die Temperatur so viel abfällt, dass das Reifen der Samen oder Körner nicht mehr möglich ist. 
Eine allgemeine Regel für die Sortenempfehlung ist, dass eine Sorte nicht mehr Wärme als 90 Prozent von der normalen effektiven Temperatursumme der Gegend brauchen darf. Wenn sie mehr Wärme für die gesamte Entwicklung bräuchte, würde sie während der kühlen Sommer zu spät reif sein. Die frühesten Getreidesorten, die mehrzeiligen Gersten, brauchen etwa 800-900 effektive Temperaturgrade (REKUNEN 1975). Sie sind also anbausicher genug noch auf dem 65. Breitgrade, wovon unsere nördlichsten Kurven da sind. Ein Sommer wie 1971 bedeutete jedoch eine Katastrofe für den gesamten Getreidebau in Nord-Finnland. Die spätesten Sommergetreidesorten, die wir nur für die südlichsten Teile Finnlands empfehlen können, reifen mit etwa 1200 Graden. Dies ist auch das Maximum an dem wir bei allem samenerzeugenden Pflanzen festhalten müssen.

\section{Die heutigen Tendenzen im Grasbau}

Gleichzeitig mit der "Grünen Revolution" der Weizenproduktion in der grossen Welt verbreitete sich in Finnland "die grüne Richtung» des Grasbaus. Sie bedeutet Erhöhung der Grasernten mit Hilfe der hohen Stickstoffmengen, in der intensiviertesten Form mit Bewässerung, und Anbau ohne Klee. Mit Stickstoff nehmen sowohl Heu- als Eiweissernte bemerkenswert zu (Tab. 1). Als Folge der grösseren Heuernten und des höheren Eiweissgehaltes ist die Eiweissproduktion pro Hektar in diesen Fällen um 60 Prozent gestiegen, als Folge der Steigerung der Stickstoffmenge auf 100 bis $200 \mathrm{~kg}$ pro Hektar.

Die dominierende Grasart im Anbau ist Timothee (Phleum pratense). Dabei baut man ganz viel Wiesenschwingel (Festuca pratensis) und in be-

Tabelle 1. Die Effekt der Stickstoffdüngung und Bewässerung auf die Heu- und Eiweissproduktion des Timotheegrases (nach Raininko 1968).

Trockensubstanz $(\mathrm{kg} / \mathrm{ha})$

Nicht Bew.

Bewässer.

Diff. $\%$

\begin{tabular}{cccc}
$\mathrm{N} 100$ & & $\mathrm{~N} 200$ & Diff. \% \\
\hline 7090 & $\rightarrow$ & 8680 & +22.4 \\
8520 & $\rightarrow$ & 10590 & +24.3 \\
$\downarrow$ & & $\downarrow$ & \\
+20.2 & & +22.0 &
\end{tabular}

Eiweisshalt (\%)
\begin{tabular}{l|clr} 
& & & \\
Nicht Bew. & N100 & & N200 \\
Bewässer. & 8.0 & $\rightarrow$ & 10.3 \\
7.5 & $\rightarrow$ & 9.0
\end{tabular}

Roheiweiss (kg/ha)

Nicht bew.

\begin{tabular}{rrrr}
$\mathrm{N} 100$ & & $\mathrm{~N} 200$ & Diff. \% \\
\hline 618 & $\rightarrow$ & 990 & +60.2 \\
712 & $\rightarrow$ & 1112 & +56.2 \\
$\downarrow$ & & $\downarrow$ & \\
+15.2 & & +12.3 &
\end{tabular}

Diff. \% 


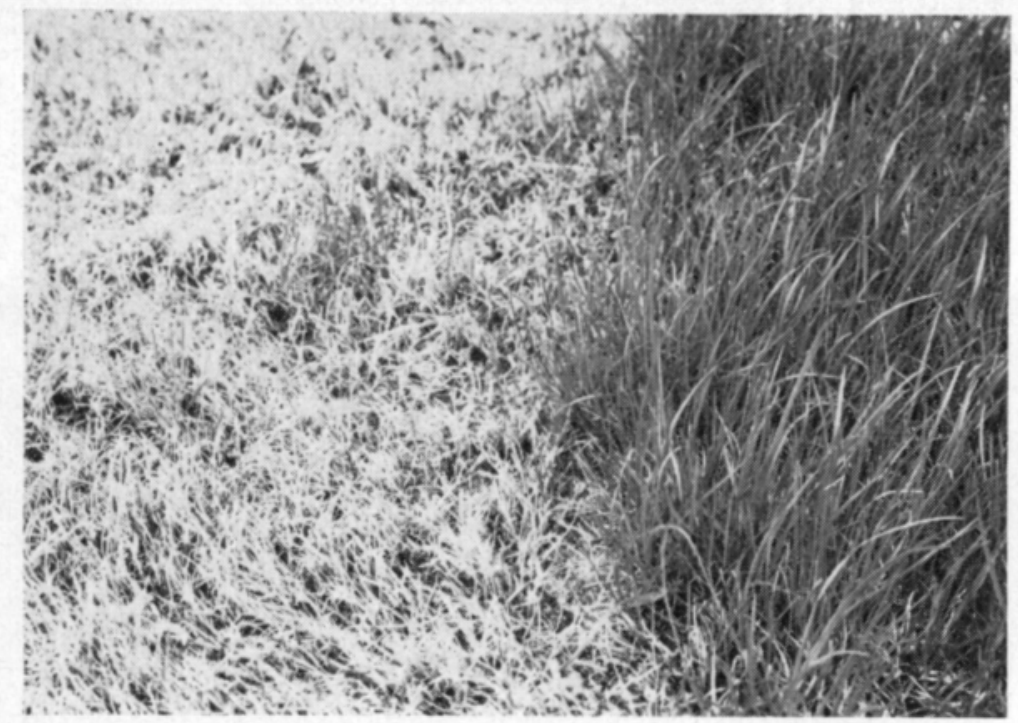

Abb. 5. Unterschied der Winterfestigkeit der zwei Sorten vom Deutschen Weidelgras (Lolium perenne) nach einer strengen Epidemie von Fusarium nivale. Links eine abgestorbene, nicht-resistente Zuchtsorte, rechts widerstandfähige Lokalsorte Valinge.

grenzten Mengen Knaulgras (Dactylis glomerata) und Deutsches Weidelgras (Lolium perenne). Der intensivierte Anbau der Gräser mit hohen Stickstoffgaben hat Zuchtprobleme mit sich gebracht, weil die Winterfestigkeit aller Gräser unter harten Düngunsverhältnissen schwächer wird.

Unter der "Grünen Richtung" ist die Winterfestigkeit immer wichtiger geworden, sowie die Bestrebungen, um die Produktivität unter intensivem Anbau mit der Resistenz gegen die Auswinterung zu kombinieren. Auch die Bedeutung der einheimischen winterfesten Grassorten ist wichtig geworden. Früher hat man ziemlich oft ausländische Sorten angebaut, wegen der Schwierigkeiten des einheimischen Samenbaus mit eigenen Sorten. Differenzen in der Winterfestigkeit zwischen den Sorten können in einigen Fallen sehr gross sein (Abb. 5). Die Sorte rechts im Bild ist von Schneeschimmel, Fusarium nivale, vernichtet worden, der einer von den gefährligsten Überwinterungskrankheiten bei uns ist. Vor allem im nördlichen Grenzgebiet des Grasbaus ist die Menge der schädlichen Überwinterungspilze gross. Ausser Fusarium sind verschiedene Typhula- und Botrytis-Arten allgemein und sie können sogar Timothee-Bestände vollkommen zerstören, obgleich Timothee unser härtestes Gras ist betreffend sowohl die Verhältnisse auf der nördlichsten Anbaugegenden als die Produktion mit hochintensiever Düngung.

Die Züchtung der Grassorten für intensivierte, hohe Eiweisserträge produzierenden Anbau ist aus zwei Gründen schwierig. Wenn wir hochgezüchtetes, südliches Material in den Kreuzungen gebrauchen, bringen wir immer Erbfaktoren mit, derer Anwesenheit die Uberwinterungsfähigkeit der Nachkommenschaft herabsetzt. Zweitens, es herrscht oft ein negatives Verhältnis zwischen Resistenz und Ertragsfähigkeit. Pflanzen, die durch natürliche 
Auswahl oder durch Züchtung gute Winterfestigkeit haben, "ziehen», sozusagen, "die Bremsen» und sind nicht fähig die ertagsproduzierende Umgebung des intensiven Anbaus zu nutzen.

Ebenso wie die Strategie der "Grünen Revolution» notwendigerweise Korrekturen braucht und ihre Entwicklungsfahrt sich zu rasch erwiesen hat, ist auch unser Grasbau mit überwiegenden Stickstoff Subjekt der Kritik geworden. Die Erhöhung der Stickstoff-Preise zusammen mit den Schwierigkeiten der Winterfestigkeitszüchtung haben das Intresse zurück auf den alten TimotheeRotklee-Anbau mit weniger Stickstoffmengen geleitet.

Rotklee ist eine sehr wertvolle Eiweissquelle. Bisher hat nur sie grössere Bedeutung als natürliche Eiweissquelle des Grasbaus in Finnland gehabt, und z. B. Luzerne ist nur sporadisch gebaut worden. Erfolgreiche Züchtung der anbausicheren Rotklee würde das Niveau unseres Grasbaus merklich heben. Rotklee ist leider die Art mit sehr schwacher Persistenz, der Anteil des Klees vermindert sich stark mit dem Alter des Grasbestandes. Die Ursache sind - wieder - die Úberwinterungskrankheiten von denen Kleekrebs, Sclerotinia trifoliorum, die allgemeinste, und schon lange als eine Kleeseuche bekannt, ist. In den letzten Jahren haben auch viele andere sogenannte Wurzeltöter des Klees ihre Gefährlichkeit gezeigt (YLIмÄKI 1967). Viele verschiedene Pilzarten verursachen innere Wurzelschädigungen wie die der Gattungen Fusarium, Rhizoctonia und Cylindrocarpon.

\section{Die Samenertrag produzierenden Eiweisspflanzen}

In der Gruppe der Samenertrag-Pflanzen hat das Futtergetreide, also Sommergerste und Hafer, selbstverständlich quantitativ dominierende Bedeutung, deren Erträge den Hauptanteil der Gesamtproduktion der Äcker unseres Lands bildet. Es ist deshalb ganz verständlich, dass schon relativ kleine Veränderungen in dem Eiweissgehalt oder der Eiweissstruktur der Gerstenoder Haferernte quantitativ gemessen zu einer grossen Verschiebung in der Gesamteiweissproduktion führt. Die Züchtung von Lysingersten kann solche Veränderungen mit sich bringen, wenn solche Sorten wirklich in der Praxis sich verbreitet werden.

In der Züchtung auf Hochlysin-Gerste haben wir als Kreuzungseltern sowohl Hiproly als auch die dänischen Risø-Mutanten gebraucht, und, wegen der Wichtigkeit der mehrzeiligen Gerste, die Lysinfaktoren auf diesem Typ zu übertragen versucht (KIVI 1977), Wir haben mit diesem Material auf gleiche Schwierigkeiten wie andere Züchter gestossen, u.a. die "Shrivelling»-Eigenschaft (geschrumpfte Körner) der Hochlysin-gerste. In den bisherigen Anbauversuchen haben die Lysin-Typen der Hiproly-Nachkommenschaften von den normalen Sorten abweichende Reaktionen auf Wärme- und Feuchtigkeitverhältnisse gezeigt (LAMPINEN 1978).

Ohne die Bedeutung zu unterschätzen, die die Lysingersten mit positiven Anbaueigenschaften in der Eiweissproduktion hätten, ist es höchst unwahrscheinlich, dass wir die Natur der Gertreidearten in dem Masse in Richtung des Eiweisserzeugers verändern können, dass wir die Futtermittelindustrie allein auf der Getreideernte aufbauen könnten, ohne Zusatz eiweissreicherer Kompo- 
nenten von den Arten derer Eiweissgehalt schon erblich höher als des Getreides ist und die Aminosäurenzusammensetzung solche, dass man mit ihren die Einseitigkeiten des Getreideeiweisses komplettieren kann.

Die in Finnland anbaubaren Sameneiweisspflanzen sind die Leguminosen Erbse und Ackerbohne und die Brassica-Ölpflanzen Raps und Rübsen. Die Züchtung dieser Arten hat während der letzten Zeit grosse Bedeutung bekommen.

\section{Die Genbank als Materialquelle in der Erbsenzüchtung}

Die Erbse ist schon lange Züchtungsobjekt gewesen. Sie ist eine alte Ackerbaupflanze im Norden, hauptsächlich für menschliche Ernährung angebaut. Nach dem zweiten Weltkrieg wurde ihr Anbau stark regeneriert, als neue Quellen der menschlichen Proteinnahrung ins Bild kamen. Heute hat die Erbse neue Bedeutung als eine gute Lösungsmöglichkeit der Futtereiweissproduktion erreicht.

Die Züchtung hat bis heute drastisch den Wachstumstypus der Erbse umgebaut. In Europa sind schon lange Zeit kurze Sorten, wie die niederländische Rondo, angebaut worden. Bei uns bleibt Rondo oft zu kurz wegen der Vorsommertrockenheit, und darum hat man, wie auch in Schweden (BINGEFORS 1978), die Züchtungsarbeit auf die morphologisch neuen Typen der sogenannten halbhohen Erbse gerichtet. Die Sorte Simo von Svalöf ist die erste zugelassene Züchtung von dieser Ideallänge, leider ist sie etwas zu spät für uns.

Wegen des Spätreifens der Erbse ist die Züchtung auf frühe Sorten von grosser Bedeutung. Sehr wichtig ist auch, dass das Blühen gleichmässig ist und vollständig beendet wird, so dass die Bestände nicht aufs neue zu blühen beginnen, wenn auch das Wetter des Spätsommers regnerisch umschlagen würde. Die Erbsenzüchter haben auch beobachtet, dass das endlose Blühen der Erbse nicht nur auf niedrige Temperatur und dem Regen beruht, sondern auch auf der Verkürzung der täglichen Lichtperiode. Deshalb bedeutet die rasche Entwicklung, die den Erbsenbestand möglichst früh im Mittsommer an das Ende der Blühphase vorbei bringt, die Sicherung gegen endloses Blühen und ungleiches Reifen. Bezüglich der Anbausicherheit ist die Erbse deutlich unter dem Niveau der Getreide. Die Lagerung versucht man mit anbautechnischen Lösungen zu vermeiden; Hafer oder standfeste Gerstensorten als Stutzpflanzen im Zusammenbau mit der Erbse. Solche Anbauteknik bringt jedoch Spezialprobleme mit sich, u.a. wegen der Konkurrenz zwischen zwei biologisch verschiedenen Partnern des Zusammenbaus.

In der Erbsenzüchtung haben wir einige neue Quellen benutzt, um die Wachstumseigenschaften der Erbse umzuwandeln: eine sehr kleinsamige und eine »blattlosen Erbsenlinie (Tab. 2). In beiden Fällen basierte die Züchtungsarbeit auf dem Material, das aus der Leningrader Genbank, dem VIR-Institut, in den 60er Jahren bekommen worden ist. Die ursprüngliche kleinsamige Erbse (K-2225) stammt aus der Türkei und der blattlose Typ (K-5110) aus dem Moskau-Gebiet. Die Anbauwerte beider Originallinien sind minimal, und sie wurden von uns mit mehreren angebauten Sorten gekreuzt.

Unter unseren Verhältnissen sind die kleinen Samen ein Anbausicherheitsfaktor sogar beim Getreide und noch mehr bei der Erbse, die eine viel grossami- 
Tabelle 2. Eigenschaften der blattlosen und kleinsamigen Erbsenlinien in den ZüchterVersuchen $1976-77$.

$\begin{array}{ccccc}\text { Samenertrag } & \text { Wachstums- } & \text { Pflanzen- } & & 1000- \\ \text { zeit } & \text { höhe } & \text { Lagerung } & \text { Samen- } \\ \text { (Rel.) } & \text { (Tage) } & (\mathrm{cm}) & (\%) & \text { gewicht }\end{array}$

(g)

Standarde

KIRI, hoch …........ 100

SIMO, halbhoch ........ 89
118

123
125

93
228

210
74

58

Neue Linien

Hja 51229

121

108 !

82

144 !

111

118

89

49 !

252

(blattlos)

Hja $51229=\left(\right.$ Maro $/$ Kalle) $\mathrm{F}_{1} / /$ Ville $/ / / k-2225$ (von der Türkei)

Hja $51237=$ k-5110 (von Moskau-Gebiet)/ Simo

gere Kulturpflanze ist. Unnötig grosse Samen trocknen sehr langsam beim Reifen, um geeignet für das Mähdreschen zu werden, und auch bei der künstlichen Trocknung nach dem Mähdreschen - das beinahe immer bei allen Korn- und Samenernten eine Notwendigkeit ist - steigen die Trocknungskosten mit steigender Samengrösse.

Auf Grund unserer Versuchsresultate ist die kleinsamige Kreuzungslinie sehr ertragsreich. Die Kleinheit der Samen wird also durch andere Ertragskomponenten kompensiert. Die Linie ist auch sehr frühreifend, was natürlich ein sehr wertvolles Charakteristikum ist. Die Differenz in der Samengrösse zwischen dieser Linie und z.B. der Rondo-Erbse ist deutlich (Abb. 6).

Die blattlose Erbse hat Samen von normaler Grösse. "Blattlos» nennt man den Erbsentyp, bei welchem das ganze Blatt rankenförming ist, und - in diesem Falle - nur die Stipulae grüne blattähnliche Organe sind (Abb. 7).

Die Idee der Züchtung eines blattlosen Typs ist, dass die Individuen eines Bestandes mit kraftigen Ranken einander stützen könnten. In diesem Typ gibt es tatsächlich weniger Lager als bei anderen Sorten. Wir haben auch beobachtet, dass beim Reifen, das also in Finnland immer im kühlenden Wetter

Abb. 6. Samenproben der sehr kleinsamigen Kreuzungslinie $\mathrm{Hja} 51229$ und

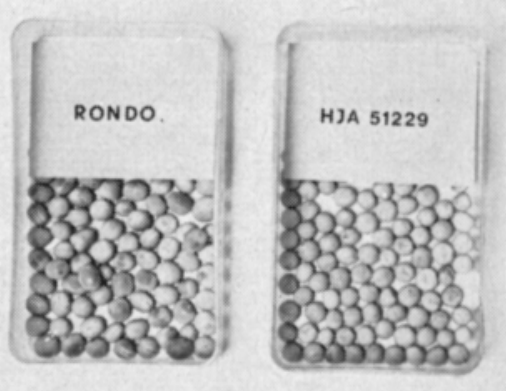
der holländischen Zuchtsorte Rondo. 


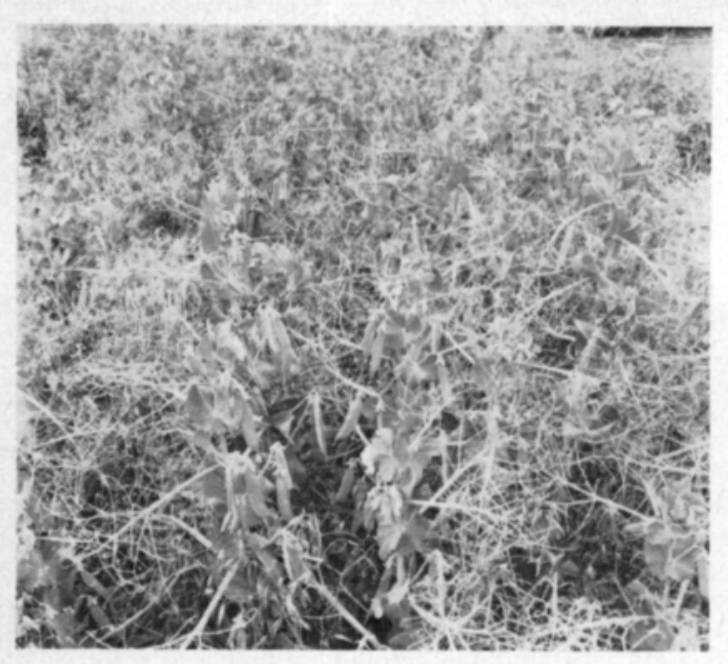

Abb. 7. Der Bestand der blattenlosen Erbsenlinie Hja 51237, die stark entwickelte Ranken aber blattförmige Stipeln hat.

des Spätsommers, wenn die Nächte schon lang und feucht sind, sich vollzieht, der Sonnenschein durch den Bestand der blattlosen Erbse besser als durch den blattreichen Bestand der normalen Sorten geht, und so ist die natürliche Trocknung mehr effektiv. Unserem Vorausweifeln ungeachtet ist es nicht zu schwer gewesen, genügend ertragreiche blattlose Linien in der Kreuzungsnachkommenschaften der K-5110-Erbse zu finden.

\section{Lokalsortiment in der Züchtung der Ackerbohne}

Als Züchtungsobjekt ist die Ackerbohne, Vicia faba, anders als die Erbse, eine neue Art. Als Kulturpflanze ist sie jedoch alt auch in Finnland. Z. B. im 18ten Jahrhundert war diese Bohne bekannt in vielen Provinzen unseres Landes (Grotenfelt 1922). Später ist sie überall ausser in Karelien verloren gegangen, wo sie zur menschlichen Ernährung bis zum zweiten Weltkrieg angebaut wurde. Einige Reste des alten Anbaus konnte man bis Ende der 60er Jahre unseres Jahrhunderts finden, u.a. im südöstlichen Grenzgebiet Finnlands, in Richtung Leningrad.

Als die Ackerbohne als eine Quelle des Futtereiweisses in den letzten Jahren des vorigen Jahrzehntes uns zu intressieren begann, wurde die Aufmerksamkeit auf dieses alte karelische Lokalsortiment gerichtet, denn alle ausländischen gezüchteten Sorten waren viel zu spät, nicht nur als Anbaumaterial sondern auch als Quellen der Züchtungsarbeit auf das Frühreifen. Das Ziel der heutigen Züchtung muss man natürlich so stellen, dass solche frühreifende Sorten für den Anbau geliefert werden können, dass die Ernte mit dem Mähdrescher einzubringen ist.

Um die Variabilität des Frühreifens der schon lange in den östlichen Teilen Finnlands angebauten karelischen Ackerbohne in der Züchtungsarbeit zu benutzen, machten wir 1969 eine Sammlungsexkursion in das südöstlichen Grenzgebiet (Hovinen und Krvi 1975). Als Resultat wurden insgesamt 12 Proben der Lokalsorten gefunden (Abb. 8). Die Sammlung fand in den letzten Momenten des traditionellen Anbaus der alten karelischen Bohne statt. In 


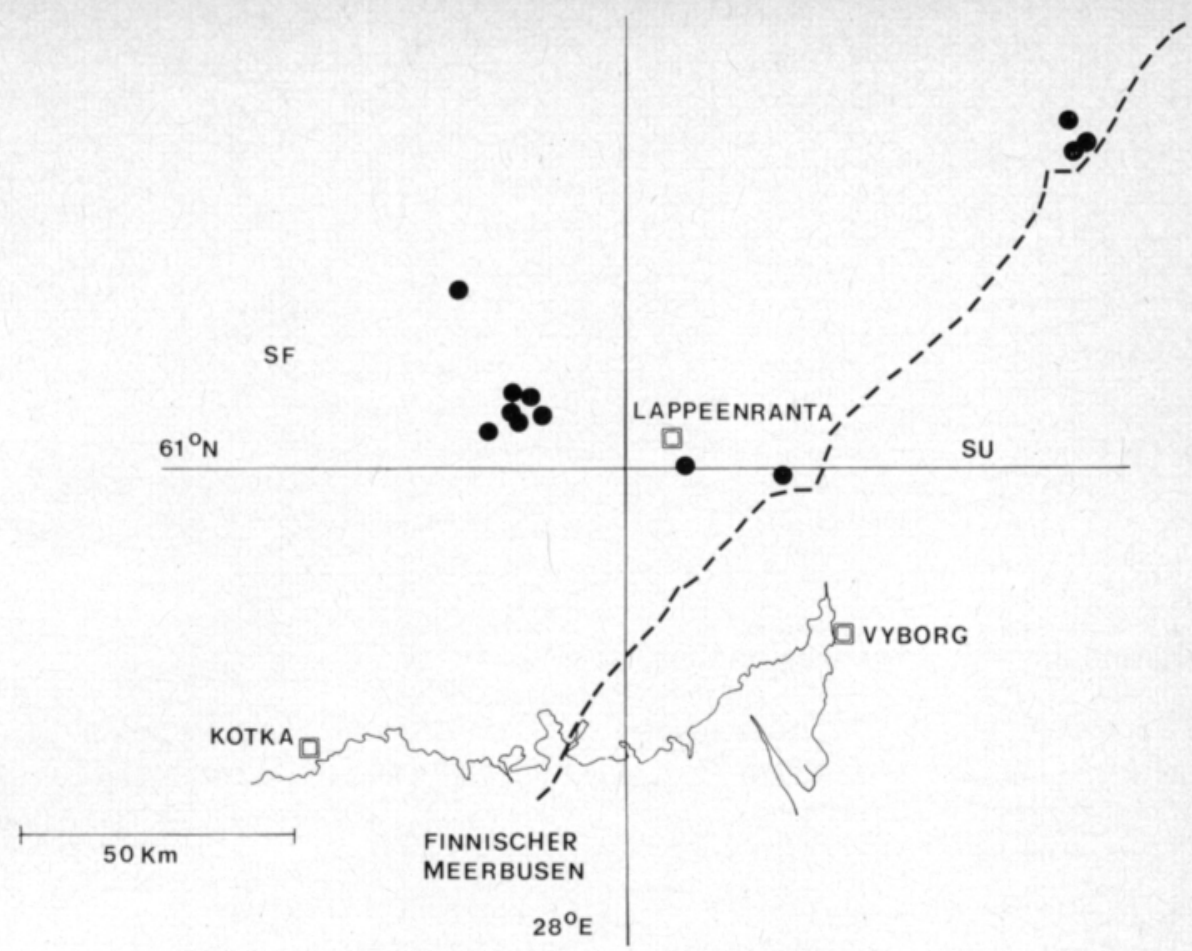

Abb. 8. Die Karte über die Fundorte der karelischen Lokalpopulationen der Ackerbohne, von denen Samenproben im Herbst 1969 gesammelt wurden.

vielen Höfen erzählte man, dass vor etwa zehn Jahren der Bohnenbau ziemlich allgemein gewesen war, aber mit dem Aussterben der ältesten Bauergeneration beendet worden war.

1977 wurde eine frühreifende einheimische Sorte der Ackerbohne (Hankkijas) Mikko zugelassen. Sie ist die Selektion aus einem Lokalstamm aus dem Dorf Tyrjä in Süd-Karelien. Diese Sorte reift etwa 6 Tage früher als die frühreifste ausländische Ackerbohne, Arla von Weibullsholm, und etwa drei Wochen früher als die deutsche Sorte Herz Freya, die in allen Sommern kaum reife Samen unter unseren Verhältnissen gibt. Die Ackerbohne ist jedenfalls eine so spätreifende Pflanzenart, dass sogar die Sorte Mikko nur für die südlichste Anbauzone Finnlands empfohlen werden kann.

Wegen ihres hohen Eiweissgehaltes - über 30 Prozent Roheiweiss von der Trockensubstanz der Samen - ist die Ackerbohne wert der weiteren Forschung und Züchtung. Die Samen der Ackerbohnen sind noch grösser als diejenigen der Erbsen. Die Kleinsamigkeit der Mikko-Sorte ist deshalb ein zielstrebiges Resultat der Züchtung (Abb. 9). Die Untersuchung der ursprünglichen Lokalpopulationen zeigte erstaunlicherweise, dass es in diesem Material viele ganz grossamige und spätreifende Individuen gab. In allen karelischen Lokalbohnen gab es nämlich eine sehr grosse genetische Variation. Die Erhaltung der späten Typen in der Population ist verständlich dadurch, dass in früheren Jahren die Bohnenbestände im unreifen Stadium geschnitten, unter dem Dach getrocknet und erst im Winter, oft sehr wahrsam mit der Hand, gedroschen wurden. 

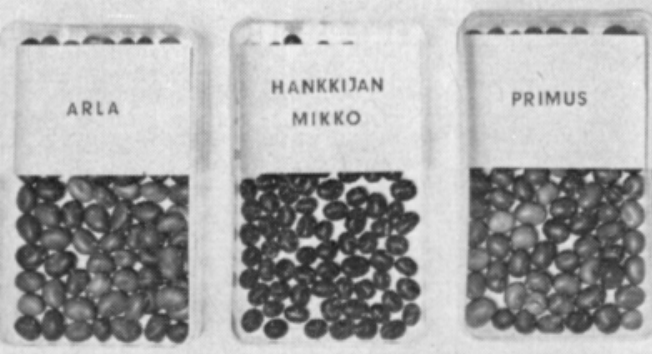

Abb. 9. Die Samenprobe der kleinund dunkelsamige Ackerbohnensorte Mikko mit zwei schwedischen Züchtungen Primus und Arla. Die Sorte Mikko ist von einer karelischen Lokalpopulation ausgewahlt worden.

\section{Mutationszüchtung bei Rübsen und Raps}

Erst während des zweiten Weltkrieges verbreitete sich in Finnland der Ölpflanzenbau. Raps und Rübsen sind also neue Kulturpflanzen bei uns. Am Anfang baute man Winterrübsen an, und er war auch ein Züchtungsobjekt. Dieses Material gehört zu einem Mutationszüchtungsprogramm der 60er Jahren, mit welchem wir u. a. die Winterfestigkeit des schwach überwinternden Rübsens $\mathrm{zu}$ verbessern versuchten. Wir wählten aus der $\mathrm{M}_{2}$-Generation verschiedene Pflanzen und vereinigten Selbstungsamen der gleichen Type als Familiennachkommenschaften (Kıvı u. a. 1974). In diesem Mutationzüchtungsprogram, mit nur einer Sorte, Rapido, als Objekt der ${ }^{30} \mathrm{Co}-B e h a n d l u n g$, machten wir den Fehler, dass die Familien zu schmalen genetischen Hintergrunde erhielten, und, wegen der Inzucht, die Nachkommenschaften nach einigen Generationen degenerierten.

Im Jahre 1975 wurde der Anbau solcher Ölpflanzensorten, deren Samen Erukasäure enthalten, vollkommen verboten. Schon früher hatte der Anbau des Winterrübsens abgenommen und die Sommerformen von Raps und Rübsen eine dominierende Stellung bekommen. Wegen der Forderungen nach erukasäurefreiem Erntegut können heute nur kanadische Sorten, deren Anbauwert, wegen des starken Lagerns und der geringeren Produktivität, nicht auf demselben Niveau wie die älteren skandinavischen Züchtungen ist, angebaut werden.

Betreffend Qualitätseigenschaften des Ölrübsens und Rapses folgt die Züchtung bei uns denselben Richtlinien wie überall. Vollkommen erukasäurefreies Öl, und Mehl mit minimaler Menge on Glykosinolaten, mit vanderen Worten die Doppel-Null-Sorten; es ist das Endziel der Arbeit.

Dabei müssen wir auch bei diesen Arten auf die Verbesserung der Ertargssicherheit hinarbeiten. Vor allem beim Raps sollten wir merklich besseres Frühreifen erreichen. In unserem Institute begannen wir die Züchtung der Sommerformen der Ölpflanzen gerade mit Raps um sein Frühreifen zu verbessern. Eine versprechende Sorte (Hankkija's) Lauri wurde 1975 zugelassen (Hovinen 1975). Sie ist beim Reifen sogar beinahe 10 Tage früher als die schwedischen Sorten. Leider war das Los des Lauri-rapses ungünstig, denn das Verbot, erukasäurehaltige Sorten anzubauen, wurde nur einige Monate 
nach dem Zulassen von Lauri veröffentlicht. Unter den nördlichen Wachstumsverhältnissen ist die Entwicklung der Pflanzen also sehr rasch und viele Sorten erreichen auch eine grössere Höhe als unter südlicheren Breitengraden. Darum haben wir in der Züchtungsarbeit kurzes Material zu erhalten versucht, durch kurze Zwergformen als Kreuzungseltern und noch mehr mit Hilfe von kurzwachsenden Mutanten. $\mathrm{Zu}$ weit in der Richtung des Zwergwuchses dürfen wir jedoch nicht unter unseren Anbauverhältnissen gehen, und jedenfalls sollten die kurzen Typen immer ein gut entwickeltes Wurzelwerk haben, weil vor allem die ersten Monate der Wachstumsperiode oft ganz trocken sein können.

\section{Zum Schluss}

Bei jeder Pflanzenart mit der wir züchterisch arbeiten, ist das Endziel gleich: ein Idiotypus, der physiologisch und morphologisch möglichst gut der Klimaumgebung und der Entwicklung der Anbautechnik entspricht.

Der Bergriff Klimaresistenz deckt sich im Norden nicht nur mit der Fähigkeit der Sorten die extremen Charakteristika des Klimas zu tolerieren sondern auch die Fähigkeit die klimatischen Besonderheiten, wie die grosse Lichtmenge und Tageslänge, zu nutzen. Gleichzeitig darf die knappe Wärme die Realisierung des genetischen Ertragspotentials der Sorten nicht verhindern.

Es ist nicht so selten, dass ein Pflanzenzüchter im Norden danach gefragt wird, ob es möglich wäre, einen von den grossen Eiweisserzeugern der Welt, wie Sojabohne oder Sonnenblume, in unserem Land als Kulturpflanze einzuführen. Obgleich der Wissenschaftler nie seinen Optimismus verlieren darf, muss er doch auch ein Realist sein, und dann dürfte - meiner Meinung nach - der Weg zu der arktischen Sojabohne oder polarischen Sonnenblume so kompliziert sein, dass es realistischer ist, die existierenden Züchtungsressourcen auf die weitere Entwicklung der an die nördlichen Klimaverhältnisse schon adaptierten Pflanzenarten zu konzentrieren.

Dieser Beitrag wurde im Gaterslebener Zentralinstitut der Akademie der Wissenschaften der DDR im Juni 1978 als Kolloqium-Vortrag gehalten. Herrn Dr. Friedrich Scholz, Gatersleben, danke ich für die kritische Durchsicht und sprachliche Úberarbeitung des Textes.

\section{VERZEICHNIS}

Bingefors, S. 1978. Influence of seeding rate on the seed yield of different growth types of peas. Sver. Utsädesf. Tidskr. 88: 69-71.

Grotenfelt, G. 1922. Peltopavun viljelys. Suom. peltokasviviljelys II: 135-139.

Hovinen, S. 1975. Hankkija's Lauri spring rape. Siemenjulkaisu 1975, Hankkija Pl. Breed. Inst.: 163 .

- \& Krvi, E. I. 1975. Field bean. Siemenjulkaisu 1975, Hankkija Pl. Breed. Inst.: 72.

Krvi, E. I. 1965. Plant breeding in Finland. Acta Agr. Scand. Suppl. 12: 52-69.

- 1967. Ilmastotekijäin vaikutus mallasohrasadon määrään ja laatuun. Mallasjuomat 1967, 11: 1-10.

- 1977. Short season barley breeding. 4th Reg. Winter Cereal Workshop, Amman, April 1977, II: 109-118. 
-, REKunen, M. \& VARIS, E. 1974. Use of induced mutations in solving problems of northern crop production. Polyploidy and Induced Mutations in Plant Breeding. Panel Proc. Ser. IAEA: $187-194$.

LAMPINEN, R. 1978. Inverkan av gödslingsnivå på protein- och lysinhalt i kärnan av höglysinkorn av Hiproly-typ. NCF, 20. Nord. Cerealistkongr., Malmö, Jułi 1978 (im Druck).

LANG, J. 1966. Der Einfluss von Klimafaktoren auf Wachstums- und Entwicklungsverlauf sowie Ertrags- und Qualitätsleistung der Braugerste, dargestellt anhand spezifischer internationaler Anbauversuche (Barley Committee, EBC). München/Weihenstephan. Diss.: $1-205$.

RAINiNko, K. 1968. The effects of nitrogen fertilization, irrigation and number of harvestings upon leys established with various seed mixtures. Acta Agr. Fenn. 112: 1-137.

Rekunen, M. 1975. Weather conditions from 1970-74. Siemenjulkaisu 1975, Hankkija Pl. Breed. Inst., 20-26.

Sarvas, R. 1965. The annual period of development of forest trees. Sitz.ber. Finn. Akad. Wiss. 1965: $211-231$.

YLIMÄKI, A. 1967. Root rot as a cause of red clover decline in leys in Finland. Ann. Agr. Fenn. 6. Suppl. 1: $1-59$.

Manuskript angekommen Dezember 11, 1978.

\title{
SELOSTUS
}

\section{Kasvinjalostuksen näkökohtia kotimaisen valkuaistuotannon toteuttamisessa viljelyn pohjoisrajoilla}

\author{
ERKKI KIVI \\ Hankkijan kasvinjalostuslaitos, 04300 Hyrylä
}

Artikkeli perustuu DDR:n tiedeakatemian Gaterslebenin keskuslaitoksen kollokviossa kesäkuussa 1978 pidettyyn esitelmään. Suomen pohjoisten viljelyolojen ja kasvinviljelymme painopistealueitten muodostamaa taustaa vasten tarkastellaan viljelyvarmojen valkuaissatoa tuottavien peltokasvien jalostamisen mahdollisuuksia.

Nurmenviljelyssä vakiintuneen vihreän linjan mukaisen tuotannon rinnalle ollaan palauttamassa tärkeintä nurmipalkokasviamme, puna-apilaa, sekä nurmisadon valkuaislähteeksi että viljelykiertojen typentuottajaksi. Tämän onnistumiseksi on puna-apilan kestävyysjalostuksessa edistyttävä ratkaisevasti.

Siemensatoa tuottavien peltokasvien arvoa rehuvalkuaisen lähteenä voidaan jalostusteitse kohentaa joko muuttamalla rehuviljain valkuaisominaisuuksia ruokinnan kannalta edullisemmaksi tai lisäämällä meillä viljeltäväksi sopeutuneiden valkuaispitoisten kasvilajien perinnöllistä viljelyvarmuutta. Kummankin tavoitteen asettaminen on perusteltua, sillä on tuskin odotettavissa, että esimerkiksi rehuohran valkuaisrakennetta pystytään siinä määrin muuttamaan, että tulevaisuudessa voitaisiin rehuseoksissa tarpeellinen valkuaistaso saavuttaa yksinomaan viljaa käyttäen.

Herneen viljelyvarmuusjalostuksessa on pyritty etenemään käyttäen VIRin geenipankista Leningradista saatua aineistoa; sekä voimakaskärhistä eli ns. lehdetöntä hernettä että erityisen pienisiemenistä alkuperää, jollaisen siemen tuleentuu ilmastossamme normaalikokoista siementä varmemmin. Kummastakin tyypistä on aineistoa virallisissa lajikekokeissa.

Härkäpavun merkitys on parhaillaan selvittelyn alaisena. Jalostustyö on perustunut pääasiassa vuonna 1969 Kaakkois-Suomessa kerättyyn karjalaiseen maatiaispapuun, joka on itäeurooppalaista tyyppiä ja jossa sekä aikaisuus että pienisiemenisyys näyttävät edustavan lajin muuntelun äärialuetta.

Öljykasvien, rypsin ja rapsin, jalostuksessa on käytetty $\mathrm{mm}$. mutaatiomenetelmää viljelyvarmuuden lisäämiseksi ja käsitelty kummastakin lajista niin öljyn kuin valkuaisrakenteiden laadun puolesta hyviä lähtöaineistoja. 